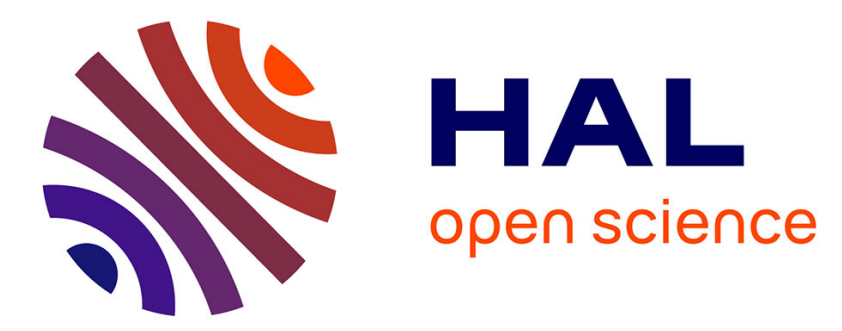

\title{
Does Resorting to Online Dispute Resolution Promote Agreements? Experimental Evidence
}

\author{
Yannick Gabuthy, Nicolas Jacquemet, Nadège Marchand
}

\section{To cite this version:}

Yannick Gabuthy, Nicolas Jacquemet, Nadège Marchand. Does Resorting to Online Dispute Resolution Promote Agreements? Experimental Evidence. European Economic Review, 2008, 52 (2), pp.259-282. 10.1016/j.euroecorev.2007.04.004 . halshs-00259453

\section{HAL Id: halshs-00259453 \\ https://shs.hal.science/halshs-00259453}

Submitted on 28 Feb 2008

HAL is a multi-disciplinary open access archive for the deposit and dissemination of scientific research documents, whether they are published or not. The documents may come from teaching and research institutions in France or abroad, or from public or private research centers.
L'archive ouverte pluridisciplinaire HAL, est destinée au dépôt et à la diffusion de documents scientifiques de niveau recherche, publiés ou non, émanant des établissements d'enseignement et de recherche français ou étrangers, des laboratoires publics ou privés.

\section{(c)(1)}

Distributed under a Creative Commons Attribution| 4.0 International License 


\title{
Does Resorting to Online Dispute Resolution Promote Agreements? Experimental Evidence*
}

\author{
Yannick Gabuthy ${ }^{\dagger}$ \\ Nicolas Jacquemet ${ }^{\ddagger}$ \\ Nadège Marchand ${ }^{\S}$
}

March 2007

\begin{abstract}
This paper presents an experiment performed to test the properties of an innovative bargaining mechanism (called automated negotiation) used to resolve disputes arising from Internet-based transactions. The main result shows that the settlement rule tends to chill bargaining as it creates incentives for individuals to misrepresent their true valuations, which implies that automated negotiation is not able to promote agreements. However, this perverse effect depends strongly on the conflict situation. When the threat that a disagreement occurs is more credible, the strategic effect is reduced since defendants are more interested in maximizing the efficiency of a settlement than their own expected profit. The implications of these results are then used to discuss the potential role of public regulation and reputation mechanisms in Cyberspace.
\end{abstract}

Keywords: Online Dispute Resolution, Electronic Commerce, Bargaining, Arbitration, Experimental Economics.

JEL classification: C78, C91, D74, K41.

\footnotetext{
${ }^{*}$ We have benefited from discussions with Sandra Cavaco, Bruno Deffains, David Dickinson, Jean-Yves Lesueur, Claude Montmarquette, Abhinay Muthoo, Jean-Louis Rullière, Jean-Robert Tyran, Marie-Claire Villeval, Romain Zeiliger, and seminar participants at GATE (University Lyon 2), BETA (University Nancy 2), and CREM (University Rennes 1). We also thank one anonymous referee for his useful comments. Financial support from the CNRS/CGP is gratefully acknowledged (this paper was part of the project "Société de l'Information").

${ }^{\dagger}$ Contact author. BETA (CNRS, University Nancy 2) - 13, place Carnot, F-54035 Nancy, France. Phone number: +33(0) 3831926 04. Fax number: +33(0) 3831926 01. E-mail: Yannick.Gabuthy@univnancy2.fr.

${ }^{\ddagger}$ University of Paris 1 Panthéon-Sorbonne and Paris School of Economics. Centre d'Economie de la Sorbonne - 106, Bd. de l'hôpital, 75013 Paris, France. Phone number: +33(0) 1440783 66. Fax number: +33(0) 1440782 47. E-mail: nicolas.jacquemet@univ-paris1.fr.

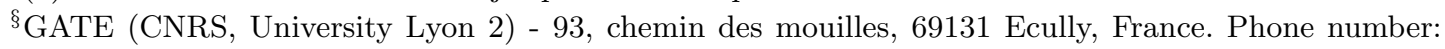
+33(0) 4728660 70. Fax number: +33(0) 4728660 90. E-mail: marchand@gate.cnrs.fr.
} 


\section{Introduction}

By reducing transaction costs, the open structure of the Internet offers businesses and consumers a new and powerful tool for electronic trade (Shapiro and Varian 1998). For example, Internet technology lowers buyer search costs by providing them a wider array of products and services from different sellers than they would have in geographically defined markets. The Internet reduces seller search costs as well, by allowing them to communicate product information cost effectively to potential buyers, and by offering sellers new ways to reach buyers through targeted advertising and one-to-one marketing (Bakos 2001, Garicano and Kaplan 2001). From this point of view, electronic commerce is widely expected to increase social welfare by intensifying competition and helping the consumers to enjoy lower prices and more choices.

However, what makes the Internet such an interesting medium for exchange creates also a number of legal obstacles which could hinder the full economic potential of electronic commerce from being reaped. The characteristics of the Internet make traditional dispute resolution through judicial procedures unsatisfactory for many controversies that arise in electronic commerce (Froomkin 1997). For instance, suppose that a buyer purchases a product from an auction site and something goes wrong with the sale (e.g., the seller may ship a damaged item or the item may have been incorrectly described in the auction). Such a problematic Internet-based transaction raises several issues about how disputes can be resolved in the virtual environment of electronic markets. First, such a transboundary transaction creates legal uncertainty about which jurisdiction is competent and about the applicable law. Second, given that the parties are physically distant, it seems difficult to haul them into court. Third, the low transaction value may simply discourages the parties to resort to a costly legal process. Consumers who participate in this type of commerce expose themselves to a heightened level of risk due to the anonymity and location of the individual making a sale or purchase円 During the medieval period, such international trade was governed by rules of private international law, the lex mercatoria $\left.\right|^{2}$ Following

\footnotetext{
${ }^{1}$ This uncertainty can explain why buyers lack trust and confidence in online transactions. For example, $62 \%$ of the european consumers declare that the lack of legal protection is the main reason for not purchasing goods online (OCDE 2002). Furthermore, despite the rapid growth in business-to-consumer e-commerce sales, they still account for a very small share of overall transactions. For example, in United States, where most Internet transactions take place, business-to-consumer penetration was just $0.48 \%$ of retail sales (Coppel 2000).

${ }^{2}$ The lex mercatoria (or law merchant) is a body of principles and regulations applied to commercial transactions and derived from the established customs of merchants and traders rather than the jurisprudence of a particular nation or state. The law merchant owed its origin to the fact that the civil law was not sufficiently responsive to the growing demands of commerce, as well as the fact that trade in medieval times was practically in the hands of cosmopolitan merchants who wanted a prompt and effective jurisdiction
} 
this idea, many authors have argued that a distinct set of substantive rules should be created in order to regulate the electronic commerce insofar as the application of legal rules which focus on the concept of territory is questionable in the case of ubiquitous computer networks such as the Internet (Johnson and Post 1996).

The need to regulate the electronic commerce has precipitated the creation of several online dispute resolution companies that offer computer-aided bargaining forums in order to settle conflict situations. These mechanisms consist of proprietary software which utilize the Internet as a means to more efficiently engage parties in automated negotiation of monetary sums. Automated negotiation appears to be an attractive solution to an important part of the jurisdictional challenges presented by the electronic commerce and promotes the idea of lex electronica by providing a self-applying settlement tool in which the legal location and anonymity of the parties do not matter: the resolution is crafted based on the preferences of the parties and does not require the physical presence of them (Mefford 1997, Rule 2002). In this context, many organizations have called for a variety of Internet companies to integrate online dispute resolution into their practices. Participants to the Hague Conference on Private International Law (11-12 December 2000) explored how online dispute resolution can improve trust for electronic commerce by helping to resolve business-to-consumer disputes. In the same way, the OECD Guidelines for Consumer Protection in the Context of Electronic Commerce, completed in December 1999, encourages the use of online dispute resolution.

Let us elaborate the automated negotiation procedure. The resolution process begins when a plaintiff registers with an online dispute resolution service provider, such as "AllSettle" or "SettleItNow" 3 The provider then uses the information provided by the plaintiff to contact the defendant party and invite him/her to participate in online dispute resolution. If the other party accepts the invitation, they will then file a response to the plaintiff's complaint 4 From this point, the software accepts sealed offers from the

(Greif et al. 1994, Benson 1996).

${ }^{3}$ The provider is simply the website delivering the online dispute resolution process. See http://www.allsettle.com/ and http://www.settleitnow.com/ respectively. For example, "SettleItNow" is the premier and independent online settlement service developed and supported in Australia.

${ }^{4}$ The defendant party has a strong incentive to accept the provider's invitation. Indeed, many of the online market sites (e.g., eBay, Amazon) have developed reputation management systems that allow the trading parties to submit a rating of the counterpart's performance in a specific transaction (Keser 2003, Cabral and Hortaçsu 2004, Houser and Wooders 2006). Recent empirical studies of online auction platforms find that such feedback systems have many positive effects in the sense reputable sellers are more likely to sell their items (Laureti et al. 2002, Resnick and Zeckhauser 2002), and can expect price premiums (Kalyanam and McIntyre 2001, Lucking-Reiley et al. 2006, Resnick et al. 2006). However, laboratory evidence shows that reputation systems fail to match the performance of one-on-one long-term relationships and a kind of public good problem may emerge (Bolton et al. 2004a, 2004b, 2005; Bolton and 
parties and determine whether a settlement occurs according to the following bargaining rule (Gabuthy 2004). Acting independently and without prior communication, plaintiff and defendant submit price offers $b_{P}$ and $b_{D}$ respectively. If the offers converge or crisscross (i.e. $b_{D} \geq b_{P}$ ), then the case is settled and the defendant has to pay the price asked by the plaintiff: $b=b_{P}$. If the offers diverge but are within a specified range (i.e. $\left.b_{D}(1+\delta) \geq b_{P}>b_{D}\right)$, then the settlement price is determined by splitting the difference between the parties' offers: $b=\left(b_{P}+b_{D}\right) / 25^{5}$ Compared to traditional bargaining, it seems that the automated negotiation procedure would be able to help the disputants to reach an agreement by providing them an additional possibility to settle their dispute (i.e. when $\left.b_{D}-b_{P}<0\right)$, through an enlargement of the settlement zone proportional to the compatibility factor, $\delta \in[0,1)$ (i.e. provided that $\left.b_{D}(1+\delta)-b_{P} \geq 0\right)$.

Our main concern is to investigate this issue by evaluating whether automated negotiation is effectively able to generate efficiency and help the parties to resolve their conflict. In order to do so, we formulate a simple model of bargaining under incomplete information that captures many of the important elements of the automated negotiation process, and then test it by conducting an experiment where we compare the individuals' behavior to the derived theoretical predictions. Laboratory experiments serve as a powerful tool for investigating many kinds of economic phenomena because they provide the means to fully control the economic environment and simulate the basic assumptions of the model under consideration (Smith 1982). Furthermore, the use of experiments to generate original data on automated negotiation is necessary for an even practical reason: the confidentiality which characterizes the online dispute resolution procedures creates important limitations to get field data. The experimental methodology offers the only way to obtain initial data on automated negotiation and therefore to shed some empirical light on how disputants respond to the incentives of this innovative settlement mechanism.

In literature, one mechanism that has been proposed to structure two-person bargaining under conditions of two-sided incomplete information is the well-known sealed bid $k$-double auction. The sealed bid $k$-double auction is a one-parameter family of bargaining rules for determining the terms of trade when a single seller and a single buyer voluntarily negotiate the transfer of an indivisible item. Under this mechanism, buyer and seller simultaneously choose bids $p_{b}$ and $p_{s}$, respectively. Trade occurs if and only if $p_{b} \geq p_{s}$; in this case, the buyer pays the seller $p=k p_{b}+(1-k) p_{s}$, where $k \in[0,1]$. In other words, when the compatibility factor is set equal to 0 , the automated negotiation Ockenfels, 2006). See Dellarocas (2005, Table 1, p.3) for a survey of online platforms providing feedback systems.

${ }^{5}$ The value ascribed to $\delta$ is common knowledge and depends upon the online dispute resolution provider $(5 \%, 20 \%, \ldots)$. 
procedure investigated in our paper reduces to the sealed bid $k$-double auction mechanism where $k=0$ (i.e. where the seller - or the plaintiff - sets the price unilaterally if an agreement is reached with the buyer - or the defendant). In order to clearly understand the analogy between our bargaining situation and the sealed bid $k$-double auction, it is helpful to think of the seller $(S)$ as a plaintiff $(P)$ and the buyer $(B)$ as a defendant $(D)$ who bargain over the price at which the plaintiff which sell his claim to the lawsuit. Starting with the seminal paper of Chatterjee and Samuelson (1983), considerable theoretical attention has been given to the sealed-bid mechanism (Leininger et al. 1989, Satterthwaite and Williams 1989, 1993, Brams and Kilgour 1996, Ausubel et al. 2002) and, recently, a number of authors have experimentally investigated its empirical properties (Daniel et al. 1998, Rapoport et al. 1998, Seale et al. 2001, Parco et al. 2004, Parco 2006 and many others) ${ }^{6}$

We depart from these previous studies precisely by focusing the analysis on the role that the compatibility factor may have on the individuals' bargaining behavior. Indeed, our main insightful result shows that, contrary to what may appear to be intuitive on an a priori basis, an increase in the parameter $\delta$ does not enhance the extent to which agreement is struck. As $\delta$ increases, the disputants are discouraged to converge on their own which induce that the automated negotiation procedure does not significantly increase the range of possible settlements: each party has a strong individual incentive to exploit strategically the compatibility factor and to adopt aggressive positions, which leads to a collective inefficient result. The results of the experiment state that the compatibility factor plagues human interaction and show that the ability of the procedure to generate efficiency increases only when the threat that a disagreement occurs becomes more credible. When the threat that a disagreement occurs is more credible, the strategic effect due to $\delta$ is reduced since defendants are more interested in maximizing the efficiency of a settlement than their own expected profit.

The remainder of the paper is organized as follows. Section 2 presents the game theoretical analysis of automated negotiation which is based on Gabuthy (2004). Section 3 then describes the experiment designed to examine the strategic behavior of subjects and presents the theoretical predictions. The results of the experiment are analyzed in Section 4, and conclusions are drawn with respect to the observed behavior and the factors contributing to it. The implications of these results are used finally in Section 5 to discuss the potential role of public regulation and reputation mechanisms in Cyberspace.

\footnotetext{
${ }^{6}$ However, most experimental papers focus the analysis on situations with $k=1 / 2$. Parco (2006) is, to the best of our knowledge, the only study reporting experimental results with $k=0$. For a survey of earlier papers, see Schotter (1990) and the collection of articles in the book Bargaining with Incomplete Information edited by Linhart et al. (1992).
} 


\section{Theoretical Background}

We consider two players, a defendant and a plaintiff who bargain over the price at which the plaintiff will sell his claim to the lawsuit. Let $v_{P}$ denote the plaintiff's reservation price (i.e. the smallest monetary sum he will accept in exchange for the damage). Similarly, let $v_{D}$ denote the defendant's reservation price (i.e. the greatest sum he is willing to pay for the damage). The valuations of the damage of the defendant and plaintiff are their private information: each party knows his own reservation price, but is uncertain about his adversary's, assessing a subjective probability distribution over the range of possible values that his opponent might hold. Specifically, each bargainer $i$ regards the opponent's reservation value $v_{j}$ as a random variable drawn from an independent uniform distribution on $\left[\underline{v}_{j}, \bar{v}_{j}\right]$, and these distribution functions are common knowledge. Therefore, the type spaces are respectively $V_{D}=\left\{\underline{v}_{D} \leq v_{D} \leq \bar{v}_{D}\right\}$ and $V_{P}=\left\{\underline{v}_{P} \leq v_{P} \leq \bar{v}_{P}\right\}$. We focus on the case of incomplete information essentially because the requirement of the complete information approach that each bargainer is assumed to know the other's preferences and payoffs is often regarded as an idealization, incapable of concrete realization.7 The automated negotiation procedure provides the following bargaining structure.

Acting independently and without prior communication, defendant and plaintiff submit simultaneous offers $b_{D}$ and $b_{P}$ respectively, defining the action spaces $B_{D}=\left\{b_{D} \geq 0\right\}$ and $B_{P}=\left\{b_{P} \geq 0\right\}$. The computer software then analyzes these proposals in order to see if a settlement has been reached. If the offers converge or crisscross (i.e. $b_{D} \geq b_{P}$ ), then the case is settled and the damage is sold at price $b=b_{P}$. If they are not, but differ by less than or equal to $\delta$ (i.e. $\left.b_{D}(1+\delta) \geq b_{P}>b_{D}\right)$, then the case is also settled and the damage is sold at price $b=\left(b_{P}+b_{D}\right) / 2$, where $\delta \in[0,1)$ is the compatibility factor associated with the automated negotiation procedure. In this latter case, the rule determines the settlement price by splitting the difference between the players' offers. If the offers differ by more than $\delta$, then the agreement is not reached. In this case, there is no settlement and no money trades hands since each player's payoff from disagreement is zero 8 In this context, a main focus of attention concerns the role and impact that $\delta$ may have on the bargaining behavior and the likelihood of a settlement. In order to conduct our analysis in a simplified manner and isolate this potential role of the compatibility factor,

\footnotetext{
${ }^{7}$ For example, the plaintiff may have more accurate information on the value of the damage, and the defendant may know whether or not he was negligent.

${ }^{8}$ While this feature seems to be in the best interest of the defendant, notice that it is a classical normalization in the literature on bargaining games under incomplete information, which is furthermore consistent with the actual automated negotiation mechanism: the defendant is not constrained to give any money to the plaintiff if no agreement is struck in the bargaining process (particularly since the plaintiff cannot take legal proceedings in such disputes).
} 
Table 1: Players' payoffs

\begin{tabular}{l|l|l} 
& \multicolumn{1}{|c|}{$\phi_{D}$} & \multicolumn{1}{|c}{$\phi_{P}$} \\
\hline \hline if $b_{D} \geq b_{P}$ & $v_{D}-b_{P}$ & $b_{P}-v_{P}$ \\
if $b_{D}(1+\delta) \geq b_{P}>b_{D}$ & $v_{D}-\left(b_{P}+b_{D}\right) / 2$ & $\left(b_{P}+b_{D}\right) / 2-v_{P}$ \\
if $b_{D}(1+\delta)<b_{P}$ & 0 & 0 \\
\hline \hline
\end{tabular}

Note. For each condition reported in row, the first column describes the payoff earned by the defendant (denoted $\phi_{D}$ ), the second column describes the payoff earned by the plaintiff (denoted $\left.\phi_{P}\right)$.

we deliberately omit from our model various other elements of the settlement mechanism that would have some role and impact on the issue under study. Especially, some restrictive assumptions are made in order to develop understanding and intuition about the role of the forces under study in a sharper manner.

First, we substitute a single-stage bargaining procedure for the multi-stage representation usually considered in the automated negotiation procedure, in which the disputants are involved in a finite sequence of the one-shot game described above. Although this might be seen as a limitation of the model, such a one-shot framework is arguably rich enough to generate a wide set of results concerning the equilibrium role of the compatibility factor 9 Through abstracting from the dynamics of the negotiation process, the single-stage bargaining procedure emphasizes the basic strategy trade-off faced by each player: by making a more aggressive offer, a player earns a greater profit in the event of an agreement but, at the same time, increases the risk of a disagreement, depending on the value of $\delta$. Second, we assume, without any loss of generality, that there is no direct cost for the parties from using the automated negotiation service - this is a simplifying modeling assumption. Currently the automated negotiation providers use a wide range of fee structures - that is, a submission fee (incurred only by the party requesting the resolution) and a settlement fee (incurred by both parties if and only if a successful settlement is reached).

Framing the single-stage bargain as a non-cooperative game, we will characterize the resulting (Bayesian) Nash equilibrium. In the event of an agreement, each player earns a profit measured by the difference between the agreed price and his reservation value $\left(b-v_{P}\right.$ for the plaintiff and $v_{D}-b$ for the defendant). In the event of no agreement, each earns a zero profit. The resulting payoffs to both the defendant and the plaintiff are summarized in Table 1 .

\footnotetext{
${ }^{9}$ Parco et al. (2004) experimentally investigate the empirical properties of multistage sealed bid $k$-double auctions (by extending the double auction to two-round of bargaining) and state a similar conclusion.
} 
We assume that each bargainer makes offers to maximize his expected profit and we restrict attention to strictly monotonic and differentiable strategies for the two players. In this static Bayesian game, a pure strategy for player $i$ is a function $b_{i}\left(v_{i}\right)$, where for each type $v_{i}$ in $V_{i}, b_{i}\left(v_{i}\right)$ specifies the action from the feasible set $B_{i}$ that type $i$ would choose if drawn by Nature $(i=D, P)$. The player $i$ 's best reply is then defined by the following maximization problem:

$$
\max _{b_{i}} \Pi_{i}=E \phi_{i} \quad(i=D, P)
$$

where the expectation is taken with respect to the probability distributions of $v_{i}$.

Then player $i$ employs a best response strategy if for each $v_{i}$ his offer is a best response against his opponent's strategy. In the automated negotiation procedure, disputants face a complex choice when choosing their offers. Both parties know that while their optimal independent behavior is to play strategically, they could be better off by bidding truthfully (i.e. $b_{D}=v_{D}$ and $b_{P}=v_{P}$ ). However, they also know that each bid they place involves a trade-off between increasing the odds of a successful trade (accomplished by placing a bid closer to their reservation value) and increasing their share of the joint gain should a settlement occur (enhanced by placing a more aggressive bid). The central idea of the analysis is to investigate how the compatibility factor affects the way individuals resolve this trade-off. It would appear at first blush that an increase in the value of $\delta$ improves the efficiency of the bargaining situation by increasing the settlement zone. In the case where $\delta=0$, an agreement occurs only when there is some "bargaining space" between the two offers (i.e. when $b_{D}-b_{P} \geq 0$ ), while a positive $\delta$ provides the parties a possibility to reach an agreement even when this "bargaining space" does not exist (i.e. when $b_{D}-b_{P}<0$, provided that $\left.b_{D}(1+\delta)-b_{P} \geq 0\right)$. The flaw in this line of reasoning is that it implicitly assumes that the bargaining strategies are unaffected by the changes in compatibility factor. This is not the case, however, since it is easy to show that changes in the compatibility factor have a drastic effect on the equilibrium behavior of the parties: ceteris paribus, when $\delta$ increases, the defendant becomes more aggressive by moving away from his reservation value (i.e. by offering a lower price). Furthermore, automated negotiation induces an asymmetric interaction between players since the compatibility factor is only assigned to the defendant's proposal. Under this bargaining rule, the plaintiff's strategy is very slightly affected by $\delta 10$

Lemma 1 Under the automated negotiation bargaining rule, the equilibrium offer strate-

\footnotetext{
${ }^{10}$ The automated negotiation puts a downward pressure on the plaintiff's demand only if we consider extreme values of $\delta$ which do not exist in the actual procedures.
} 
gies are:

$$
\begin{gathered}
b_{D}^{*}\left(v_{D}, \delta\right)=\alpha(\delta) v_{D} ; b_{P}^{*}\left(v_{P}, \delta\right)=\beta(\delta) v_{P}+\gamma(\delta) \bar{v}_{D} \\
\text { where } \alpha(\delta)=\frac{2(1+\delta)}{\left(\delta^{2}+4 \delta+2\right)}, \beta(\delta)=\frac{2(1+\delta)}{(2+\delta)^{2}} \text { and } \gamma(\delta)=\frac{4(1+\delta)^{3}}{(2+\delta)^{2}\left(\delta^{2}+4 \delta+2\right)} .
\end{gathered}
$$

Proof See the Appendix.

As mentioned in the Introduction, the case where $\delta=0$ in the automated negotiation procedure is equivalent to the case where $k=0$ in the sealed bid $k$-double auction mechanism. However, we consider a linear characterization of the equilibrium, which is different from the piece-wise linear representation assumed in Chatterjee and Samuelson (1983) 11 As an illustration, consider the special case in which $\delta=0$ and $v_{P}\left(v_{D}\right)$ is uniformly distributed over the closed interval $[0,60]([40,100])$. A straightforward manipulation of Lemma 1 gives $b_{D}^{*}\left(v_{D}\right)=v_{D}$ and $b_{P}^{*}\left(v_{P}\right)=1 / 2 v_{P}+50$ (for all $v_{i}, i=D, P$ ), while Chatterjee and Samuelson (1983) specify the following strategies for the two players 12

$$
\begin{gathered}
b_{P}^{C S}=\frac{1}{2} v_{P}+50 \quad \text { for all } \quad 0 \leq v_{P} \leq 60 \\
b_{D}^{C S}=\mid \begin{array}{cc}
v_{D} & \text { if } 40 \leq v_{D}<80 \\
80 & \text { if } 80 \leq v_{D} \leq 100
\end{array}
\end{gathered}
$$

The linear characterization has been introduced to simplify the analysis and is consistent with our experimental data which do not reveal any discontinuity in the individuals' bargaining behavior.

Following Lemma 1, the compatibility factor has two opposite implications on the settlement zone, defined by:

$$
b_{D}(1+\delta) \geq b_{P}
$$

First, by providing the parties an additional possibility to reach an agreement, the compatibility factor increases the settlement zone for given bargaining strategies: it is straightforward to show that the compatibility factor has a positive impact on the lefthand side of (2).

However, at the same time, the compatibility factor leads the defendant to become more aggressive and move away from his true valuation (while the plaintiff's demand is

\footnotetext{
${ }^{11}$ The multiplicity of equilibria is a well known feature of such games. We differ from Chatterjee and Samuelson (1983) in the way we get a unique equilibrium.

${ }^{12}$ These intervals correspond to the low conflict situation in our experimental design (see Figure 1, $\mathrm{p}$ 11). The piece-wise linear equilibrium solution of Chatterjee and Samuelson (1983) can be derived from equations given by Parco (2006, p. 414).
} 
constant):

$$
\frac{\partial b_{D}^{*}\left(v_{D}, \delta\right)}{\partial \delta}=\frac{-2\left(\delta^{2}+2 \delta+2\right)}{\left(\delta^{2}+4 \delta+2\right)^{2}} v_{D} \leq 0, \text { since } \delta>0 \text { and } v_{D} \geq 0
$$

The defendant's offer strategy is sensitive to changes in the compatibility factor in a natural way. In the case where $\delta=0$, the defendant's equilibrium proposal coincides with his reservation value (i.e. $b_{D}=v_{D}$ for all $v_{D}$ ). The intuition behind this result is the following. When an agreement is reached, the case is settled at price $b=b_{P}$, therefore the rule is equivalent to granting the plaintiff the right to make a first and final offer that the defendant can accept or reject. In this instance, the transaction price is determined solely by the plaintiff's demand, while the defendant's offer serves only to determine whether there is an agreement or not. The defendant's dominant strategy is then to make a truthful offer in order to maximize the probability of settlement. On the contrary, when the compatibility factor increases the marginal increment in profit associated with a slightly more aggressive offer becomes weighted more heavily than the possible loss, if as a result of the change, an agreement is precluded. Concerning the plaintiff's offer strategy, we could think intuitively that the defendant's aggressiveness would force the plaintiff to adopt a more concessionary bargaining behavior in order to increase the probability to reach an agreement. This is not the case however because the more compromising party, while enhancing her chances of reaching an agreement, does so at the expense of lowering her expected payoff.

Given these two opposite implications, the global effect of the compatibility factor on the probability that a settlement occurs is not significant, except for extreme values of $\delta$ which do not exist in the real automated negotiation procedures. The gain in efficiency due to the increase in the "potential" settlement zone is approximately offset by the efficiency loss due to the parties' strategic behavior, causing the "actual" settlement zone to be slightly affected by changes in $\delta$.

Proposition 1 Under the automated negotiation bargaining rule, the compatibility factor does not improve the efficiency of the settlement zone.

The intuition behind this result is the following: the parties are more reluctant to concede during negotiations because the threat that a disagreement occurs is less credible for high values of $\delta$. This result is consistent with the predictions of the arbitration models and the well-known chilling effect (Farber 1981): automated negotiation tends to "chill" bargaining as it creates incentives for individuals to misrepresent their true valuations and discourage them to converge on their own (i.e. with $b_{D} \geq b_{P}$ ). In fact, the computer 
software seems to become a neutral third party who drives the parties' strategies outside the range of potential negotiated settlements. This result suggests that the automated negotiation design is not a good way for increasing the likelihood of a settlement: each party has a strong individual incentive to exploit strategically the compatibility factor and adopt aggressive positions, which leads to a collective inefficient result. However, while this result is theoretically appealing, we have no idea about whether it characterizes bargaining realities. The next section aims at filling the gap.

\section{Experimental protocol}

\subsection{Experimental design}

We experimentally implement the negotiation game described in Section 2 . At the beginning of each period, each subject $i$ is assigned a private reservation value $v_{i}(i=D, P)$. Then, the defendant and the plaintiff choose simultaneously a bidding price (i.e. $b_{D}$ for the defendant and $b_{P}$ for the plaintiff). The experiment is based on a factorial $2 \times 2$ design combining two levels of conflict (high/low) with two levels of the compatibility factor $(\delta=0 / \delta=30 \%)$.

The basic question in our study is whether the compatibility factor affects the bargaining behavior of the parties and under which circumstances does it increase the probability of reaching an agreement. Therefore, in some of the treatments, participants play under the conditions of "pure" negotiation in which there is no compatibility factor (i.e. $\delta=0$ ) and the parties may reach an agreement only if their offers are strictly convergent (i.e. $\left.b_{D} \geq b_{P}\right)$. In other treatments, subjects interact under the conditions of automated negotiation where the compatibility factor equals $30 \%$ and the parties have the possibility to settle their dispute even when $b_{D}<b_{P}$ (provided that $1.3 b_{D} \geq b_{P}$, since $\delta=0.3$ ) ${ }^{13}$ However, we can think intuitively that the ability of the automated negotiation mechanism to generate efficiency (if any) depends on the extent of the conflict between the parties. Therefore, the following treatments are introduced in order to analyze whether the impact of the compatibility factor depends on the conflict situation. In a first case, the private values $v_{D}$ and $v_{P}$ are independently drawn from a uniform distribution with supports $\{40,41, \ldots, 100\}$ and $\{0,1, \ldots, 60\}$ respectively, while in a second case the respective uniform distribution sets are $\{20,21, \ldots, 100\}$ and $\{0,1, \ldots, 80\}$. The last case obviously characterizes a high conflict situation, as illustrated in Figure 1.

Notice that, whatever the conflict situation, the plaintiff's valuation may be equal

\footnotetext{
${ }^{13} \delta=30 \%$ appears to be a reasonable value in order to give the subjects a sufficient opportunity to take into account this parameter.
} 
Figure 1: Conflict situations used in the experiment

$v_{P}$

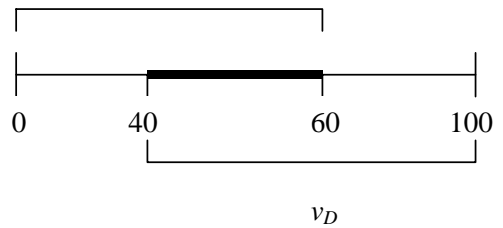

(a) Low conflict situation
$v_{P}$

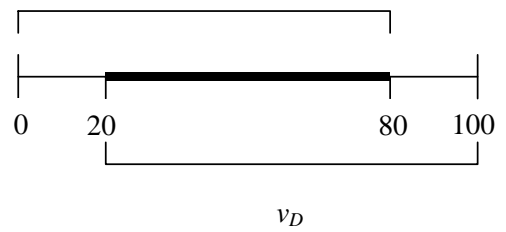

(b) High conflict situation

Note. In each Figure, $v_{P}$ denotes the private value of the plaintiff, $v_{D}$ the private value of the defendant. The bold line illustrates the conflict zone settled by the treatment, set either to Low conflict (Figure a) or High Conflict (Figure b).

to 0 ( since $\underline{v}_{P}=0$ ), while the defendant's valuation is strictly positive ( $\operatorname{since} \underline{v}_{D}>0$ ). This assumption may seem to be surprising since we could intuitively consider that the plaintiff should inherently award a positive value to his claim. However, the assumption made on the lower bound of the plaintiff's private value has two motivations. First, the players' reservation values may be considered as their disagreement payoffs in the bargaining process. In our analysis, we implicitly assume that $i /$ there is no cost for the parties from using the automated negotiation procedure, and $i i /$ the parties may incur some difficulties to resort to alternative dispute resolution systems if they fail to reach an agreement during the automated bargaining (due to jurisdictional challenges presented by such disputes). In other words, the intuition behind the zero value ascribed to $\underline{v}_{P}$ is that the plaintiff may have no outside option and gets nothing if no settlement is struck in the bargaining process. Second, assuming that $\underline{v}_{P}=0$ allows us to extend the settlement zone (e.g. $v_{D}-v_{P}$ when $\delta=0$ ) in order to increase the likelihood of a settlement (for given bargaining strategies). This way, we avoid that the main result of the paper concerning the (in)efficiency of automated negotiation be due to the incentives given to the plaintiff in the experimental protocol.

The information provided to the participants maps the information structure of the game analyzed in Section 2. At the end of each period, each pair of subjects was therefore privately informed on whether or not they have reached an agreement, about the price to be paid by the defendant, their own bid, their own payoff in the current period and their total profit up to this time. As well, payments were determined according to the automated negotiation rules and the submitted offers. The theoretical predictions for the experimental game are consequently derived from the background developed above, as summarized in Table 2 ,

Recall that our basic issue is a positive question: given that the automated negotiation 
Table 2: Overview of theoretical predictions

\begin{tabular}{r|l|l} 
& \multicolumn{1}{|c}{$\delta=0$} & \multicolumn{1}{c}{$\delta=30 \%$} \\
\hline \hline Equilibrium Bidding Strategies & & \\
Plaintiff & $b_{P}^{*}\left(v_{P}\right)=0.5 v_{P}+50$ & $b_{P}^{*}\left(v_{P}, 30 \%\right)=0.49 v_{P}+50.49$ \\
Defendant & $b_{D}^{*}\left(v_{D}\right)=v_{D}$ & $b_{D}^{*}\left(v_{D}, 30 \%\right)=0.79 v_{D}$ \\
\hline Efficient Bidding Strategies & & \\
Plaintiff & $b_{P}^{e}=v_{P}$ & $b_{P}^{e}\left(v_{P}, 30 \%\right)=v_{P}$ \\
Defendant & $b_{D}^{e}=v_{D}$ & $b_{D}^{e}\left(v_{D}, 30 \%\right)=v_{D}$ \\
\hline \hline Equilibrium Settlement Zone & $S Z^{*}=v_{D}-0.5 v_{P}-50$ & $S Z^{*}(30 \%)=1.03 v_{D}-0.49 v_{P}-50.49$ \\
\hline \hline Efficient Settlement Zone & $S Z^{e}=v_{D}-v_{P}$ & $S Z^{e}(30 \%)=1.3 v_{D}-v_{P}$ \\
\hline \hline
\end{tabular}

Note. The conflict situation is neutral on the formal theoretical predictions. The settlement zone $(S Z)$ is given by $S Z=b_{D}^{*}\left(v_{D}, \delta\right)(1+\delta)-b_{P}^{*}\left(v_{P}, \delta\right)$, where $b_{D}^{*}($.$) and b_{P}^{*}($.$) are the players' equilibrium strategies.$

procedure is designed in a particular manner, does the individual's behavior corresponds to what the designer intended, and what causes the deviations? Therefore, summarizing the theoretical predictions, the experimental data are analyzed according to the three following hypotheses.

Hypothesis 1 In equilibrium, when $\delta=0$ :

- The defendant adopts a truth revealing behavior. The equilibrium offer coincides with his reservation value: $b_{D}^{*}\left(v_{D}\right)=b_{D}^{e}\left(v_{D}\right)=v_{D}$.

- The plaintiff's behavior is untruthful, his proposal being higher than his reservation value: $b_{P}^{*}\left(v_{P}\right)>b_{P}^{e}\left(v_{P}\right)=v_{P}$.

According to Hypothesis 1 , the settlement rule associated with $\delta=0$ induces a truthful bidding behavior on the part of the defendant, while the plaintiff's asking price is biased upward with respect to his valuation. As a result, even when the defendant values the damage more highly than the plaintiff, a successful settlement may be impossible: $S Z^{*}<$ $S Z^{e}$.

Hypothesis 2 (Chilling effect) In equilibrium, when $\delta$ is increased (set equal to 30\%):

- The defendant becomes more aggressive, adopting an under-bidding behavior:

$$
b_{D}^{*}\left(v_{D}, 30 \%\right)<b_{D}^{e}\left(v_{D}, 30 \%\right)=v_{D}
$$

- The plaintiff's behavior remains the same, over-bidding according to:

$$
b_{P}^{*}\left(v_{P}, 30 \%\right)>b_{P}^{e}\left(v_{P}, 30 \%\right)=v_{P}
$$


As stated in Hypothesis 2, only the defendant's behavior is affected by the rise in the compatibility factor, moving bidding behavior to more aggressive - untruthful - offers. Increasing the compatibility factor hence fails to improve efficiency: it is still the case that not all mutually beneficial agreements can be attained via the automated negotiation procedure: $S Z^{*}(30 \%)<S Z^{e}(30 \%)$. The parties are then discouraged to converge on their own, resulting in a chilling effect.

Hypothesis 3 When the extent of the conflict increases, the settlement zone decreases ; an agreement is hence less likely.

When the conflict situation is high, the distribution sets induce a reduced settlement zone and do not affect the equilibrium bargaining strategies (for given reservation values). However, we could think intuitively that this result does not characterize bargaining realities: we conjecture that a higher conflict situation should encourage more concessionary behavior by the parties in order to increase the probability to reach an agreement. In other words, the disputants should take more reasonable bargaining positions by moving closer to their true values because the threat that a disagreement occurs is more credible in a high conflict situation. In this context, we believe that this concessionary behavior could compensate for the perverse effect induced by the compatibility factor. Such a result would imply that the conflict situation alters fundamentally the way the individuals use the compatibility factor: in a high conflict situation, the parties could be incited to use the compatibility factor more efficiently (as a means to increase their chances to reach an agreement) and less strategically (as a means to increase their payoffs).

\subsection{Experimental Procedures}

In all experimental conditions described above, subjects participated as a defendant or as a plaintiff in a sealed-bid double auction (one defendant and one plaintiff forming a group). Role assignment remained the same throughout the entire session. Each pair of participants had to agree on the exchange price of the claim. 14 The experiments were run in the GATE experimental laboratory with 160 participants over a total of 8 sessions, with each session comprising 40 periods, hence providing 6400 observations. The participants were randomly recruited from a subject pool of students of several universities and the graduate school of management (Lyon). All of them were inexperienced in auction experiments and no subject participated in more than one of the sessions. In each of the 40 periods, the

\footnotetext{
${ }^{14}$ In the experiment, we used a more neutral terminology: a buyer (the defendant) and a seller (the plaintiff) bargain over the transfer of an indivisible good (the claim). A successful trade is determined by the automated negotiation mechanism.
} 
defendant-plaintiff pairs were re-matched such that the same defendant-plaintiff pair did not interact in two consecutive periods. Therefore, in our setup, all the theoretical results hold for all periods: since interaction is anonymous and one-shot, the 40 periods are repetitions of static games and not a dynamic game giving rise to further equilibria. In other words, the random-matching design allow us to minimize (if not completely eliminate) reputation effects.

Upon arrival, participants were randomly assigned to a specific computer terminal. In the beginning of each session, instructions were distributed and read aloud (an English translation of the original instructions in french as well as raw data are available from the authors upon request). Clarifying questions were asked and answered privately. Then, we asked the participants to fill in a control questionnaire in order to check for understanding. Only after all questions had been correctly answered, the experiment started. The experiment was computerized using the REGATE software (Zeiliger 2000). On average, each session lasted one hour, excluding payment of subjects. All amounts were given in ECU (Experimental Currency Unit), with conversion into Euros at a rate of 2 Euros for 100 ECUs upon completion of the session. The total payment was the sum of the single payoffs of the 40 periods plus a 2 Euros show-up fee. Each subject earned on average slightly more than 14 Euros.

\section{Experimental Results}

Following the above discussion, our three hypothesis are tested here by assessing the impact of the compatibility factor and the conflict situation on bidding behavior of each party and the resulting conflict resolution implemented by the negotiation procedure.

\subsection{Bidding Behavior}

We provide a preliminary picture of individual behavior of plaintiffs and defendants using the following indexes:

- Relative deviation from the linear equilibrium strategy - This index $\left(I_{i}^{*}\right)$ measures the relative difference between observed proposal $\left(b_{i}\right)$ and the equilibrium bidding strategy $\left(b_{i}^{*}\right)$ :

$$
I_{i}^{*}=\frac{b_{i}-b_{i}^{*}}{b_{i}^{*}} \quad(i=D, P)
$$

- Relative deviation from efficiency - This index $\left(I_{i}^{e}\right)$ measures the relative difference 
Figure 2: Overview of bidding behavior

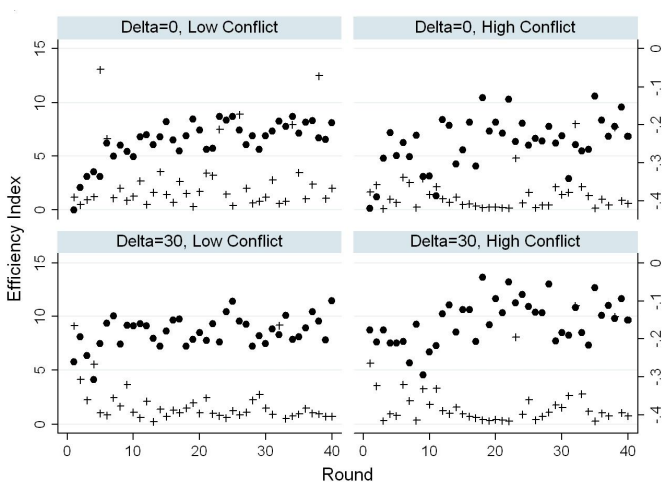

(a) Plaintiffs

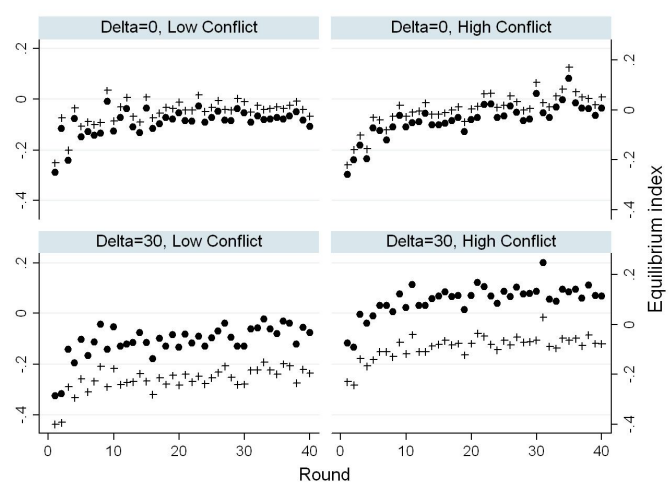

(b) Defendants

Legend. + Efficiency index (Y axis plotted on the left); • Equilibrium index (Y axis plotted on the right).

Note. Average observed deviation from equilibrium and efficiency for plaintiffs (Figure a) and defendants (Figure b) under $\delta=0$ (upper part) or $\delta=30 \%$ (bottom part) and under Low (left-hand side Figures for each party) or High (right-hand side Figures for each party) conlict situation. The indexes are calculated using (3) and (4)

between observed proposal $\left(b_{i}\right)$ and the efficient bidding strategy $\left(b_{i}^{e}\right)$ :

$$
I_{i}^{e}=\frac{b_{i}-b_{i}^{e}}{b_{i}^{e}} \quad(i=D, P)
$$

By way of definition, each index provides a comparison between observed behavior and either equilibrium or efficient strategies. A positive value of $I_{i}^{*}$ indicates that the plaintiff (defendant) follows a more (less) aggressive pricing strategy than the Nash equilibrium. Similarly, a positive value of $I_{i}^{e}$ reflects an over-bidding behavior, the plaintiff (defendant) asking for a compensation higher (offering more) than his reservation value - a negative value of each index indicates the other way round.

Figure 2 plots the average indexes across rounds for each party, depending on the conflict situation and the value of the compatibility factor. In line with the results summarized in Table 2, the two indexes mechanically coincides for defendant when $\delta=0$, since equilibrium and efficient strategies are the same. An overall salient feature is a slight learning pattern in the first ten periods, suggesting that experience with the mechanism matters in bidding behavior. This will be addressed in the econometric analysis of the data 15

\footnotetext{
${ }^{15}$ The efficiency index sometimes appears to be driven by outliers, dropping to very high values. This is due to an over-reaction of indexes to deviations associated with very low private values. Just as an illustration, all 531 individual observations for which the efficiency index is above 2 have private values lower than 21. This upper bound on private values falls to 15 when only those observations for which the efficiency index is above 3 (what amounts to 382 observations out of our 6400) are considered.
} 
We now turn to a discussion of parties' behavior in line with experimental treatments. Consider first our benchmark situation, namely bidding behavior when the compatibility factor is set equal to 0 . The defendants' proposals appear to be relatively efficient. Indeed, the overall average indexes amount to $I_{D}^{*}=I_{D}^{e}=-5 \%$ or $-6 \%$, depending on the conflict situation. On the opposite, plaintiffs' behavior seems largely inefficient since the price required is strongly higher than their reservation values (the overall average efficiency index is $I_{P}^{e}=73 \%$ when the conflict is low, $32 \%$ when the conflict is high). Regarding comparisons with equilibrium behavior, Parco (2006) states that conferring a price-setting power to the information advantaged player induces a less aggressive behavior. This seems to hold as well in our game, characterized by symmetric information conditions. While defendants choose bids close to equilibrium, plaintiffs adopt strategies less aggressive than those predicted by the Nash equilibrium (the average efficiency index is $I_{P}^{*}=-24 \%$ and $-23 \%$ under low and high conflict situations). As a result, the defendants' deviation from equilibrium is significantly lower than the plaintiffs' one (Mann-Withney U test and Kolmogorov-Smirnov test, both with p-value: $p=0.0001$ ).

Result 1 When $\delta=0$, the defendants' behavior is more truthful revealing than the plaintiffs' behavior.

This asymmetric behavior between defendants and plaintiffs supports the first hypothesis. This makes intuitive sense by referring to the parallel between our double auction game and the first- and second-price sealed-bid auctions in which several purchasers compete to obtain a good.

1. The problem confronting a defendant in automated negotiation (with $\delta=0$ ) is strategically similar to the problem faced by a buyer in a second-price auction. In second-price auctions, the highest bidder gets the object and pays the second highest bid. From a theoretical point of view, this procedure is efficient since bidders have a dominant strategy of bidding up to their private valuation, irrespective of attitudes toward risk (Vickrey 1961). Indeed, the bid made by the player has no impact on the transaction price he pays and affects only his probability of winning (which is maximized by offering the highest price corresponding to his reservation value) ${ }^{16}$

\footnotetext{
${ }^{16}$ However, this behavior is not consistent with laboratory experiments in which subjects are found to exhibit a consistent pattern of overbidding (Kagel et al. 1987, Kagel and Levin 1993, Harstad 2000). Economists have very little understanding of why it happens. Recently, Cooper and Fang (2006) provide an explanation by considering that individuals overbid because they derive positive utility from winning, over and beyond any monetary payoffs. See also Morgan et al. (2003) and Andreoni et al. (2006) for alternative explanations of this phenomenon.
} 
Similarly, in automated negotiation (with $\delta=0$ ), the settlement price is determined solely by the plaintiff's demand (i.e. $b=b_{P}$ ). The settlement rule is therefore equivalent to granting the plaintiff the right to make a first and final offer that the defendant can accept or reject. The defendant's offer serves only to determine whether there is an agreement or not. The defendant maximizes the probability to reach an agreement - conditional on earning positive profits - by bidding an amount corresponding to his valuation.

2. The problem confronting a plaintiff in automated negotiation (with $\delta=0$ ) is strategically similar to the problem faced by a buyer in a first-price auction. In first-price auctions, the highest bidder gets the object and pays the amount he bids. The decision-making in first-price auctions is more complex than that in second-price auctions since each players' bid involves a trade-off between increasing the probability of winning (by placing a bid closer to their reservation value) and increasing their profit (by placing a more aggressive bid). The experimental literature shows that buyers underbid compared to efficiency (because of this trade-off) and overbid compared to the equilibrium (in order to improve their chances of winning). This standard result is developed in Kagel and Roth (1995) ${ }^{17}$

Similarly, in automated negotiation (with $\delta=0$ ), the plaintiff's proposal determines both his profit and the probability of conflict resolution. Therefore, he adopts an inefficient behavior which consists of asking for an amount higher than his reservation value. However, he tends to be less aggressive than predicted by the Nash equilibrium in order to improve the likelihood of a settlement (as buyers maximize their probability of winning in first-price auctions).

Now turn to bidding behavior under our mechanism of interest (i.e. when a positive compatibility factor is implemented). Under $\delta=30 \%$, remember that when the proposals do not converge but differ by less than $\delta$, the bargaining rule determines the settlement price by splitting the difference between the parties' offers. Therefore, contrary to the case where $\delta=0$, the defendant faces a trade-off between enhancing the probability to reach an agreement and increasing his expected payoff. In that sense, the defendants reply to the change in the compatibility factor in a natural way. As shown in Figure 2, this settlement rule indeed induces defendants to move away from their valuations and behave closer to the equilibrium prediction (the average indexes across rounds are $I_{D}^{e}=-27 \%$ or $I_{D}^{e}=-14 \%$, and $I_{D}^{*}=-8 \%$ or $I_{D}^{*}=8 \%$, depending on the conflict situation). The

\footnotetext{
${ }^{17}$ See also Cox et al. (1988), and Harrison (1989).
} 
strategic problem faced by the plaintiff is not fundamentally modified by the split-thedifference rule. Whatever the level of $\delta$ is, the plaintiff faces a similar trade-off since the settlement price corresponds to his own demand (as soon as the offers converge or overlap). As a result, the compatibility factor does not significantly affect the plaintiff's behavior. When $\delta=30 \%$, the plaintiffs are therefore still encouraged to adopt inefficient behavior which is closer to the equilibrium prediction (average indexes amount to $I_{P}^{e}=69 \%$ or $I_{P}^{e}=48 \%$ and $I_{P}^{*}=-18 \%$ or $I_{P}^{*}=-14 \%$, depending on the conflict situation).

The statistical significance of the patterns described above are assessed using the following regression. The price offered by a party $n$ at time $t, y_{n t}$, is specified as a linear combination of the covariates, denoted $X_{n t}$. This includes our main variables of interest, namely the level of the compatibility factor, the conflict situation and their interaction. We also account for learning by including a dummy variable set equal to one during the first ten periods only. Last, the reservation value is included jointly with its squared and cubic values in order to test the linearity of the strategies 18 In this linear specification, $y_{n t}=X_{n t} \beta+\varepsilon_{n t}$, we account for the panel dimension of our observations by considering a composed error model: $\varepsilon_{n t}=u_{n}+w_{n t}$. The individual specific error term $u_{n}$ is assumed normal in the estimation and captures the distribution of heterogeneity in the population. The model is separately estimated by maximum likelihood for plaintiffs and defendants. The results are presented in Table 3. First note that the two coefficients on the last dummy variable strongly suggest that learning occurs during the first ten periods. The structural motives underlying bidding behavior are therefore better estimated by regressions that include such dummies.

As expected, the proposals of both parties are increasing in their reservation values. The coefficients on powers of the reservation values moreover support the linearity of the bidding strategies followed by both plaintiffs and defendants. Regarding the impact of the settlement rule on bidding behavior, the estimated coefficients on the compatibility factor variable support the asymmetric impact stated in Hypothesis 2.

Result 2 The compatibility factor does not significantly affect the plaintiffs' behavior, while defendants become more aggressive by offering lower compensations.

As a result, automated negotiation tends to "chill" bargaining as it creates incentives for individuals to misrepresent their true valuations and discourage them to converge on their own. Beyond this overall effect, the coefficient on the interaction variable suggests

\footnotetext{
${ }^{18} \mathrm{~A}$ similar analysis is developed by Radner and Schotter (1989) who show that the behavior of the subjects is consistent with the linear equilibrium. Notice, however, that their analysis is quite distinct from ours since they consider symmetric prior distributions and the midpoint trade rule (i.e. $k=1 / 2$ ). Their experiment 4 set $k=1$ but was only briefly mentioned without results or analysis.
} 
Table 3: Determinants of proposals by plaintiffs and defendants

\begin{tabular}{|c|c|c|c|c|}
\hline & \multicolumn{2}{|c|}{ Plaintiff } & \multicolumn{2}{|c|}{ Defendant } \\
\hline & Coef. & St. Dev. & Coef. & St. Dev. \\
\hline Constant & $35.60^{* * *}$ & $\overline{(1.550)}$ & 1.18 & $(3.459)$ \\
\hline Compatibility factor & 3.30 & $(2.023)$ & $-14.99^{* * *}$ & $(2.336)$ \\
\hline Conflict situation & $-3.57^{*}$ & $(2.027)$ & -0.34 & $(2.338)$ \\
\hline Interaction & 2.97 & $(2.861)$ & $9.30^{* * *}$ & $(3.303)$ \\
\hline Reservation value $\left(v_{i}\right)$ & $0.38^{* * *}$ & $(0.069)$ & $1.18^{* * *}$ & $(0.168)$ \\
\hline$v_{i}^{2}$ & 0.00 & $(0.002)$ & -0.00 & $(0.003)$ \\
\hline$v_{i}^{3}$ & 0.00 & $(0.000)$ & 0.00 & $(0.000)$ \\
\hline Learning & $-2.98^{* * *}$ & $(0.376)$ & $-5.20^{* * *}$ & $(0.359)$ \\
\hline Log-likelihood & -12227 & 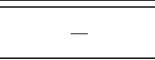 & -12321 & - \\
\hline \multicolumn{5}{|c|}{ "Legend. Significance levels: ${ }^{*} 10 \%,{ }^{* *} 5 \%,{ }^{* * *} 1 \%$. } \\
\hline \multicolumn{5}{|c|}{$\begin{array}{l}\text { Note. Random effects OLS regression. The dependent variable is the bid. The } \\
\text { Compatibility factor is treated as a Dummy variable, set equal to } 1 \text { if } \delta=0.3 \\
\text {; The High conflict situation is included as dummy variable ; The Interaction } \\
\text { variable is set equal to one when } \delta=0.3 \text { under an high conflict situation, } 0 \\
\text { otherwise; The Learning variable is equal to one during the first ten periods. } \\
\text { The regression is run on } 80 \text { individuals }(N=80) \text { observed during } 40 \text { periods } \\
(T=40) \text {. Each regression is therefore run on } 3200 \text { observations. }\end{array}$} \\
\hline
\end{tabular}

that the impact of the compatibility factor is significantly affected by the conflict situation. This last variable fundamentally alters the way the defendant uses the compatibility factor:

Result 3 The compatibility factor associated with higher conflict situations encourages defendants to adopt a more concessionary behavior.

The threat of a disagreement becomes more credible in a high conflict situation, which encourages defendants to use the compatibility factor less strategically. In this context, a higher conflict reduces the chilling effect : the defendant uses the automated negotiation mechanism more efficiently in order to increase the probability to reach an agreement conditional on positive earnings. The asymmetry between defendants and plaintiffs still remains effective, and the plaintiffs' proposals are not affected by the compatibility factor in higher conflict situations.

Overall, our main variables of interest strongly impact the way the surplus raised by an agreement is split between parties. More interestingly with regard to efficiency, we now turn to the ability of the settlement rule to promote an agreement between parties.

\subsection{Conflict Resolution}

An overview of the observed conflict resolution is provided in Figure 3. For each difference in the private values of defendants and plaintiffs (hence measured by $v_{D}-v_{P}$ ), we draw 
Figure 3: Average differences in the bid posted by plaintiffs and defendants

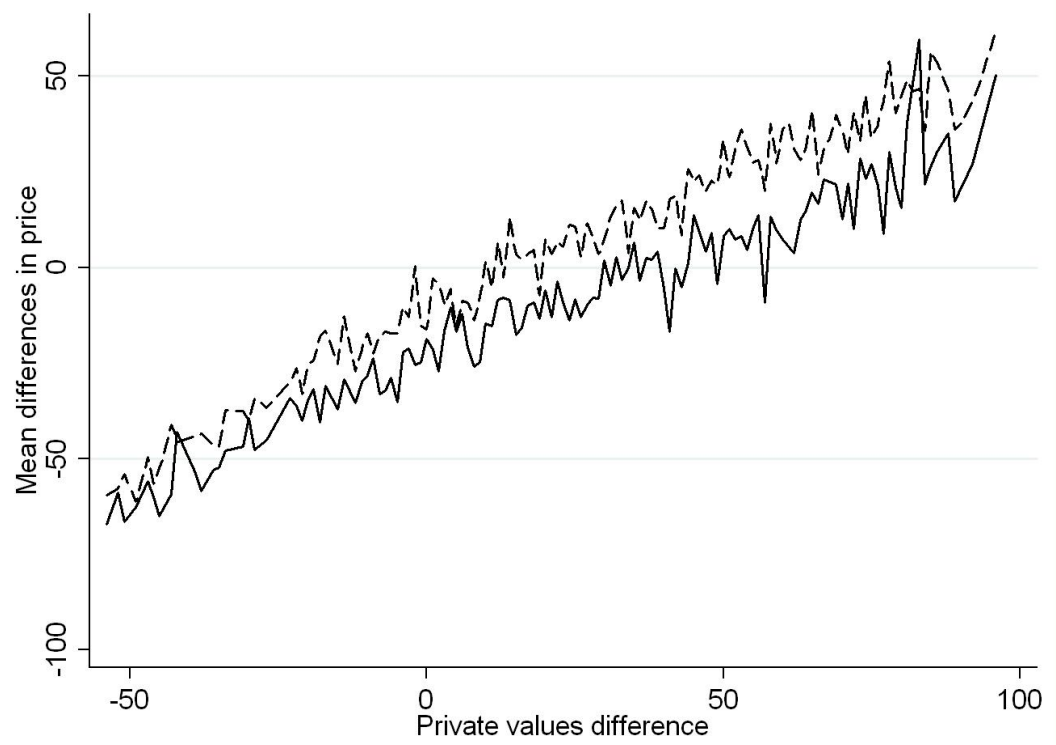

Legend. Dash line: $\delta=0$; Solid line $\delta=30 \%$.

Note. The figure plots the average difference between defendant's and plaintiff's bids (measured as $b_{D}-b_{P}$ ) for a given difference between private values (measured as $v_{D}-v_{P}$ ).

the average difference between bids $\left(\right.$ i.e. $b_{D}-b_{P}$ ) when the compatibility factor is set equal to 0 (dash line) or $30 \%$ (solid line). A "perfect" conflict resolution would imply that price differences are positive as soon as the difference between private values is so. The observed trend does support an increase in bid differences in line with the difference between private values.

Regarding the impact of the compatibility factor, the figure illustrates the strategic exploitation by parties of the settlement rule stressed above. As compared to what happens when $\delta=30 \%$, the defendants' offers are more often higher than the plaintiffs' demands when the compatibility factor is set equal to 0 (i.e. the dash line is almost always above the solid one). The parties therefore seems more reluctant to concede during negotiations following an increase in the compatibility factor. Under the automated negotiation procedure the occurrence of a "straight" settlement then appears to be less likely, due to parties being discouraged to converge on their own.

Even though individual behavior is an important determinant of conflict resolution, automated negotiation is precisely aimed at improving the ability of parties to reach an agreement. Indeed, actual settlements differ from straight ones due to the compatibility factor enlarging the settlement zone under automated negotiation. To illustrate this point, 
Table 4: Settlement rates

\begin{tabular}{l||c|c||c} 
& Low conflict & High conflict & Overall \\
\hline \hline$\delta=0$ & $76.50 \%(612)$ & $54.25 \%(434)$ & $65.38 \%(1046)$ \\
$\delta=30 \%$ & $69.25 \%(554)$ & $57.75 \%(462)$ & $63.50 \%(1016)$ \\
\hline \hline Overall & $72.88 \%(1166)$ & $56.00 \%(896)$ & $64.44 \%(2062)$ \\
\hline \hline
\end{tabular}

Note. Each cell provides the proportion of observations that reached an agreement in the treatment defined by row/column combination.

The corresponding number of observations is provided in parenthesis.

we summarize the actual settlement rates per level of the compatibility factor and conflict situation in Table 4. Despite this mechanism, the automated negotiation procedure appears to fail in promoting efficiency. The compatibility factor induces a slight overall increase in the conflict rate, the rate of agreements decreasing from $65.38 \%$ when $\delta=0$ to $63.50 \%$ when $\delta=30 \%$.

Desegregating those settlement rates as regards to the conflict situation, a huge heterogeneity however appears. In low conflict situations, the chilling effect associated with the compatibility factor seems to over-compensate for the positive effect of this factor on the probability to reach an agreement: the settlement rate decreases from $76.5 \%$ (when $\delta=0$ ) to $69.25 \%$ (when $\delta=30 \%$ ). In higher conflict situations, the chilling effect is reduced since the threat that a disagreement occurs is more credible. This implies that automated negotiation in this case slightly promotes agreements, as suggested by the increase in the settlement rate from $54.25 \%$ (when $\delta=0$ ) to $57.75 \%$ (when $\delta=30 \%$ ).

The robustness of those observations is checked using a Probit regression. The ability to reach an agreement is specified as a latent variable, denoted $y_{n t}^{*}$, and linked to the observed settlement, $y_{n t}$, through:

$$
y_{n t}= \begin{cases}1 & \text { if } y_{n t}^{*} \geq 0 \\ 0 & \text { otherwise }\end{cases}
$$

The latent variable is assumed linear in the observables: $y_{n t}^{*}=X_{n t} \beta+\varepsilon_{n t}$, where $X_{n t}$ includes the same variables as before, namely: the levels of the compatibility factor and the conflict situation as well as their interaction (dummies), the private values of both the plaintiff and the defendant. The panel dimension is accounted for by estimating a random effects model, in which the error term is decomposed into and individual specific term, a time-specific term and an i.i.d. variable: $\varepsilon_{n t}=u_{n}+v_{t}+w_{n t}$.

As is well known (e.g. Greene 2003, p. 667), the marginal effects of explanatory variables differ from the estimated coefficients in Probit models. Calculated marginal 
Table 5: Determinants of conflict resolution

\begin{tabular}{|c|c|c|c|c|}
\hline & \multicolumn{2}{|c|}{ Estimation results } & \multicolumn{2}{|c|}{ Marginal effects } \\
\hline & Coef. & (St. Dev.) & Coef. & (St. Dev.) \\
\hline Constant & $-1.67^{* * *}$ & $(0.118)$ & $-0.56^{* * *}$ & $(0.048)$ \\
\hline Compatibility factor & -0.14 & $(0.099)$ & -0.05 & $(0.033)$ \\
\hline High conflict situation & 0.07 & $(0.087)$ & 0.02 & $(0.029)$ \\
\hline Interaction & $0.31^{* * *}$ & $(0.113)$ & $0.10^{* * *}$ & $(0.037)$ \\
\hline$v_{P}$ & $-3.57^{* * *}$ & $(0.120)$ & $-1.19^{* * *}$ & $(0.056)$ \\
\hline$v_{D}$ & $5.32^{* * *}$ & $(0.135)$ & $1.78^{* * *}$ & $(0.072)$ \\
\hline$\rho$ & $0.06^{* * *}$ & $(0.018)$ & & \\
\hline Log-likelihood & -1207 & & & \\
\hline Chi-squared & 22.73 & & & \\
\hline$\%$ of predicted observations & $83.66 \%$ & & & \\
\hline
\end{tabular}

Legend. Significance levels: ${ }^{*} 10 \%, * * 5 \%, * * * 1 \%$.

Note. Probit regression. The dependent variable is a dummy, set equal to one when the defendant/plaintiff pair has reached an agreement. The Compatibility factor is treated as a Dummy variable, set equal to 1 if $\delta=0.3$; The High conflict situation is included as dummy variable ; The Interaction variable is set equal to one when $\delta=0.3$ under an high conflict situation, 0 otherwise; The reservation values of the plaintiff $\left(v_{P}\right)$ and defendant $\left(v_{D}\right)$ are included in thousands. 3200 observations are used.

effects are thus provided jointly with estimation results in Table 5 . First, remember that the higher the value placed on the damage by the plaintiff (defendant), the higher the amount he demands (offers). One should therefore expect an agreement to be less and less likely as the private value of defendants is decreased and/or the private value of plaintiffs is increased. This rather intuitive pattern is supported by our data, since the coefficients on private values are both significant with the expected sign. Both marginal effects are moreover close in absolute value, suggesting a symmetric impact of private values on the likelihood of reaching an agreement.

Regarding the way the settlement rule influences conflict resolution, the estimation results corroborate the above observations. We summarize them as our last result.

Result 4 The compatibility factor does not significantly affect the likelihood of a settlement. In higher conflict situation, the compatibility factor increases the likelihood of a settlement.

The first part of Result 4 is consistent with Hypothesis 2: despite its purpose, the compatibility factor does not improve the efficiency of the settlement zone. As stressed before, the reason is the strategic reply of parties to the settlement rule overcomes the apparent improvement in the conflict resolution for given offers. Due to a lower chilling 
effect, an high conflict situation however improves the ability of the compatibility factor to promote conflict resolution.

\section{Conclusion}

In this paper, we analyze the theoretical properties of the automated negotiation procedure and derive equilibrium strategies for the plaintiff and the defendant. The empirical properties of this innovative bargaining mechanism are also tested by performing a set of experiments. In particular, we consider the factors that appear to determine whether a subject places bids that are close to, or exaggerated from, his reservation value. Following the experimental results, we can state that the value of the compatibility factor and the extent of the conflict are such factors: the compatibility factor creates a chilling effect insofar as the settlement rule deliberately splits the difference between the disputants' proposals and give them incentives to adopt aggressive bargaining positions, while this effect is reduced when the extent of the conflict is higher.

The intuition behind these results is consistent with a basic finding of studies on arbitration which show that arbitration procedures, by lowering the overall cost of disagreement, increases the incidence of disagreement: bargaining with arbitration lessens the likelihood that bargainers will reach a settlement on their own (Currie and McConnell 1991, Ashenfelter et al. 1992, Dickinson 2004). In other words, despite the significant evidence that arbitrators do not simply split the difference (Bloom 1986, Farber and Bazerman 1986), there does appear to be empirical evidence of a chilling effect to arbitration 19 Another source of evidence is the narcotic effect of arbitration: going to arbitration engenders "dependence" on the procedure (Currie 1989, Bolton and Katok 1998, 2004). More precisely, a dispute decreases the probability a dispute will happen in subsequent rounds, however this learning effect with arbitration tends to be lower than it is without.

Furthermore, our experimental results raise the crucial question of how to enforce agreements reached via automated negotiation and give some elements of thinking about the potential role of public regulation and reputation mechanisms in Cyberspace. Indeed, such automated negotiation systems are offered by private companies on the electronic justice market and are, by definition, contractual. Therefore, the problem is to know how a private electronic constraint can ensure that the disputants will enter in this type of procedure ex ante and will accept not to renegotiate the settlement ex post (given that nothing other than public justice can force an agent to settle a conflict and/or execute a

\footnotetext{
${ }^{19}$ Theoretically, Farber (1981) shows that what appears to be splitting the difference may actually be disputants strategically bracketing their final offers around the expected arbitration award.
} 
settlement decision).

In this context, we could argue that the reputation mechanisms existing on the Internet would be a powerful way to enforce such contracts. As mentioned in the Introduction, many of the online market sites (e.g. eBay, Amazon) offer reputation management systems that allow the trading parties to submit a rating of the counterpart's performance. Therefore, we could conjecture that if one of the disputants does not respect the settlement stated by the automated algorithm, then a naming and shaming strategy would occur and allow to enforce it. Furthermore, the question concerning the acceptance (or not) of the settlement by the parties arises obviously only if the latter managed to reach an agreement during the automated negotiation process. In other words, what happens if no agreement is reached at the end of the negotiation? This question is not trivial given the poor economic performance of the mechanism and we could think intuitively that the parties will recourse to an alternative dispute resolution system, such as arbitration or mediation (which are also available online).

In summary, this paper may be considered as a first step in the empirical investigation of online dispute resolution. Indeed, following the above arguments, it is obvious that further experiments will have to be done before a clear picture of how the type of mechanisms studied here perform well. Such experiments would take into account, for example, the impact of reputation and the role of alternative dispute resolution mechanisms. In this context, we feel confident that the types of question raised by our experiment will be central to the final unraveling of the puzzles presented by the computer-aided bargaining systems available in the online environment.

\section{Appendix: Proof of Lemma 1}

Considering linear strategies, we assume that the defendant's strategy is $b_{D}\left(v_{D}\right)=a_{D}+$ $c_{D} v_{D}$ and the plaintiff's one is $b_{P}\left(v_{P}\right)=a_{P}+c_{P} v_{P}$. Then $b_{D}$ is uniformly distributed on $\left[a_{D}+c_{D} \underline{v}_{D}, a_{D}+c_{D} \bar{v}_{D}\right]$ and $b_{P}$ is uniformly distributed on $\left[a_{P}+c_{P} \underline{v}_{P}, a_{P}+c_{P} \bar{v}_{P}\right]$.

Following Table 1, the maximization problem (1) for the defendant and plaintiff respectively becomes

$$
\begin{aligned}
& \max _{b_{D}}\left(v_{D}-\frac{b_{D}+a_{P}+c_{P} \underline{v}_{P}}{2}\right) \frac{b_{D}-a_{P}-c_{P} \underline{v}_{P}}{c_{P}\left(\bar{v}_{P}-\underline{v}_{P}\right)}+\left(v_{D}-\frac{b_{D}(4+\delta)}{4}\right) \frac{\delta b_{D}}{c_{P}\left(\bar{v}_{P}-\underline{v}_{P}\right)} \\
& \max _{b_{P}}\left(b_{P}-v_{P}\right) \frac{a_{D}+c_{D} \bar{v}_{D}-b_{P}}{c_{D}\left(\bar{v}_{D}-\underline{v}_{D}\right)}+\left(\frac{b_{P}(4+3 \delta)}{4(1+\delta)}-v_{P}\right) \frac{\delta b_{P}}{c_{D}\left(\bar{v}_{D}-\underline{v}_{D}\right)(1+\delta)}
\end{aligned}
$$


The first-order conditions for which yield

$$
b_{D}=\frac{2(1+\delta)}{\delta^{2}+4 \delta+2} v_{D}, \text { and } b_{P}=\frac{2(1+\delta)}{(2+\delta)^{2}} v_{P}+\frac{2(1+\delta)^{2}}{(2+\delta)^{2}}\left(a_{D}+c_{D} \bar{v}_{D}\right)
$$

Given the linear strategies $b_{D}\left(v_{D}\right)=a_{D}+c_{D} v_{D}$ and $b_{P}\left(v_{P}\right)=a_{P}+c_{P} v_{P}$, by manipulating (5), the linear equilibrium strategies are

$$
b_{D}^{*}\left(v_{D}, \delta\right)=\frac{2(1+\delta)}{\delta^{2}+4 \delta+2} v_{D}, \text { and } b_{P}^{*}\left(v_{P}, \delta\right)=\frac{2(1+\delta)}{(2+\delta)^{2}} v_{P}+\frac{4(1+\delta)^{3}}{(2+\delta)^{2}\left(\delta^{2}+4 \delta+2\right)} \bar{v}_{D}
$$

\section{References}

[1] Andreoni, J., Y-K. Che, and J. Kim (2006), "Asymmetric Information about Rivals' Types in Standard Auctions: An experiment ", Working Paper, University of Wisconsin-Madison.

[2] Ashenfelter, O.C., J. Currie, H.S. Farber, and M. Spiegel (1992), "An Experimental Comparison of Dispute Rates in Alternative Arbitration Systems", Econometrica, 60, 1407-1433.

[3] Ausubel, L., Cramton, P., and R.J. Deneckre (2002), "Bargaining with Incomplete Information", in R.J. Aumann and S. Hart (eds), Handbook of Game Theory, vol. 3, Amsterdam: Elsevier.

[4] Bakos, Y. (2001), "The Emerging Landscape for Retail E-Commerce", Journal of Economic Perspectives, 15, 69-80.

[5] Benson, B.L. (1996), "The Law Merchant", Working Paper, Florida State, Department of Economics.

[6] Bloom, D.E. (1986), "Empirical Models of Arbitrator Behavior under Conventional Arbitration", Review of Economics and Statistics, 68, 578-585.

[7] Bolton, G.E., and E. Katok (1998), "Reinterpreting Arbitration's Narcotic Effect: An Experimental Study of Learning in Repeated Bargaining", Games and Economic Bahavior, 25, 1-33.

[8] Bolton, G.E., and E. Katok (2004), "The Role of Learning in Arbitration: An Exploratory Experiment", in S. Huck (ed), Advances in Understanding Strategic Behavior: Game Theory, Experiments, and Bounded Rationality, New York: Palgrave McMillan. 
[9] Bolton, G.E., E. Katok, and A. Ockenfels (2004a), "Bridging the Trust Gap in Electronic Markets: A Strategic Framework for Empirical Studies ", in E. Ackali, J. Geunes, P.M. Pardalos, H.E. Romeijn and Z.J. Shen (eds), Applications of Supply Chain Management and E-Commerce Research, Springer.

[10] Bolton, G.E., E. Katok, and A. Ockenfels (2004b), "How Effective are Electronic Reputation Mechanisms? An Experimental Investigation", Management Science, 50, 1587-1602.

[11] Bolton, G.E., E. Katok, and A. Ockenfels (2005), "Cooperation among Strangers with Limited Information about Reputation ", Journal of Public Economics, 89, 1457-1468.

[12] Bolton, G.E., and A. Ockenfels (2006), "The Limits of Trust in Economic Transactions", Working Paper, Penn State University.

[13] Brams, S.J., and D.M. Kilgour (1996), "Bargaining Procedures that Induce Honesty", Group Decision and Negotiation, 5, 239-262.

[14] Cabral, L., and A. Hortaçsu (2004), "The Dynamics of Seller Reputation: Theory and Evidence from eBay", CEPR Discussion Paper: 4345.

[15] Chatterjee, K., and W. Samuelson (1983), "Bargaining under Incomplete Information", Operations Research, 31, 835-851.

[16] Cooper, D.J., and H. Fang (2006), "Understanding Overbidding in Second Price Auctions: An Experimental Study", Cowles Foundation Discussion Paper: 1557.

[17] Coppel, J. (2000), "E-commerce: Impacts and Policy Challenges", Working paper, OCDE, Economics Department.

[18] Cox, J.C., V.L. Smith, and J.M. Walker (1988), "Theory and Individual Behavior of First-Price Auctions", Journal of Risk and Uncertainty, 1, 61-69.

[19] Currie, J. (1989), "Who Uses Interest Arbitration? The Case of British Columbia's Teachers 1947-1981", Industrial and Labor Relations Review, 42, 363-379.

[20] Daniel, T.E., D.A. Seale, and A. Rapoport (1998), "Strategic Play and Adaptative Learning in the Sealed-Bid Bargaining Mechanism", Journal of Mathematical Psychology, 42, 133-166.

[21] Dellarocas, C. (2005), "Reputation Mechanisms", in T. Hendershott (ed), Handbook on Economics and Information Systems, Amsterdam: Elsevier. 
[22] Dickinson, D.L. (2004), "A Comparison of Conventional, Final-Offer, and "Combined" Arbitration for Dispute Resolution", Industrial and Labor Relations Review, 57, 288-301.

[23] Farber, H.S. (1981), "Splitting-the-Difference in Interest Arbitration", Industrial and Labor Relations Review, 35, 70-77.

[24] Farber, H.S., and M.H. Bazerman (1986), "The General Basis of Arbitrator Behavior: An Empirical Analysis of Conventional and Final-Offer Arbitration", Econometrica, $54,1503-1528$.

[25] Froomkin, M.A. (1997), "The Internet as a Source of Regulatory Arbitrage", in B. Kahin and C. Nesson (eds), Borders in Cyberspace: Information Policy and the Global Information Structure, Cambridge: MIT Press.

[26] Gabuthy, Y. (2004), "Online Dispute Resolution and Bargaining", European Journal of Law and Economics, 17, 353-371.

[27] Garicano, L., and S.N. Kaplan (2001), "The Effects of Business-to-Business Ecommerce on Transaction Costs", Journal of Industrial Economics, 49, 463-485.

[28] Greene, W H. (2003), Econometric Analysis (Fifth edition), Prentice Hall: New-York $(\mathrm{NJ})$.

[29] Greif, A., P. Milgrom, and B.R. Weingast (1994), "Coordination, Commitment and Enforcement: The Case of the Merchant Guild", Journal of Political Economy, 102, 745-776.

[30] Harrison, G.W. (1989), "Theory and Misbehavior of First-Price auctions", American Economic Review, 79, 749-762.

[31] Harstad, R.M. (2000), "Dominant Strategy Adoption and Bidders' Experience with Pricing Rules", Experimental Economics, 3, 261-280.

[32] Houser, D., and J. Wooders (2006), "Reputation in Auctions: Theory and Evidence from eBay", Journal of Economics and Management Strategy, 15, 353-369.

[33] Johnson, D.R., and D. Post (1996), "Law and Borders- The Rise of Law in Cyberspace", Stanford Law Review, 48, 1367-1401.

[34] Kagel, J.H., R.M. Harstad, and D. Levin (1987), "Information Impact and Allocation Rules in Auctions with Affiliated Private Values: A Laboratory Study", Econometrica, 55, 1275-1304. 
[35] Kagel, J.H., and D. Levin (1993), "Independent Private Value Auctions: Bidder Behaviour in First-, Second- and Third-Price Auctions with Varying Numbers of Bidders", Economic Journal, 103, 868-879.

[36] Kagel, J.H., and A.E. Roth (1995), The Handbook of Experimental Economics, Princeton: Princeton University Press.

[37] Kalyanam, K., and S. McIntyre (2001), "Return on Reputation in Online Auction Markets", Working Paper, Leavey School of Business, Department of Marketing.

[38] Keser, C. (2003), "Experimental Games for the Design of Reputation Management Systems", IBM Systems Journal, 42, 498-506.

[39] Laureti, P., F. Slanina, Y-K. Yu, and Y-C. Zhang (2002), "Buyer Feedback as a Filtering Mechanism for Reputable Sellers", Physica A, 316, 413-429.

[40] Leininger, W., P.B. Linhart, and R. Radner (1989), "Equilibria of the Sealed-Bid Mechanism for Bargaining with Incomplete Information", Journal of Economic Theory, 48, 63-106.

[41] Linhart, P.B., R. Radner, and M.A. Satterthwaite (eds), (1992), Bargaining with Incomplete Information, San Diego: Academic Press.

[42] Lucking-Reiley, D., D. Bryan, N. Prasad, and D. Reeves (2006), "Pennies from eBay: The Determinants of Price in Online Auctions", Working Paper, Vanderbilt University.

[43] Mefford, A. (1997), "Lex Informatica: Foundations of Law on the Internet", Indiana Journal of Global Legal Studies, 5, 211-236.

[44] Morgan, J., K. Steiglitz, and G. Reis (2003), "The Spite Motive and Equilibrium Behavior in Auctions", Contributions to Economic Analysis and Policy, vol. 2, n1, Article 5.

[45] Myerson, R.B., and M.A. Satterthwaite (1983), "Efficient Mechanisms for Bilateral Trading", Journal of Economic Theory, 29, 265-281.

[46] OCDE (2002), "Les consommateurs sur le marché en ligne: les lignes directrices de l'OCDE, trois ans après", Rapport du comité de la politique à l'égard des consommateurs.

[47] Parco, J.E. (2006), "Price-Setting Power and Information Asymmetry in Sealed Bidding", Managerial and Decision Economics, 27, 413-434. 
[48] Parco, J.E., A. Rapoport, D.A. Seale, W.E. Stein, and R. Zwick (2004), "Multistage Sealed-Bid $k$-Double-Auctions: An Experimental Study of Bilateral Bargaining", in S. Huck (ed), Advances in Understanding Strategic Behavior: Game Theory, Experiments, and Bounded Rationality, New York: Palgrave McMillan.

[49] Radner, R., and A. Schotter (1989), "The Sealed-Bid Mechanism: An Experimental Study", Journal of Economic Theory, 48, 179-220.

[50] Rapoport, A., T.E. Daniel, and D.A. Seale (1998), "Reinforcement-Based Adaptive Learning in Asymmetric Two-Person Bargaining with Incomplete Information", $E x$ perimental Economics, 1, 221-253.

[51] Resnick, P., and R. Zeckhauser (2002), "Trust Among Strangers in Internet Transactions: Empirical Analysis of eBay's Reputation System", in M.R. Baye (ed), The Economics of The Internet and E-Commerce, vol. 11, Amsterdam: Elsevier.

[52] Resnick, P., R. Zeckhauser, J. Swanson, K. Lockwood (2006), "The Value of Reputation on eBay: A Controlled Experiment", Experimental Economics, 9, 79-101.

[53] Rule, C. (2002), Online Dispute Resolution for business, San Francisco: Jossey-Bass Press.

[54] Satterthwaite, M.A., and S.R. Williams (1989), "Bilateral Trade with the Sealed Bid $k$-Double Auction: Existence and Efficiency", Journal of Economic Theory, 48, 107-133.

[55] Satterthwaite, M.A., and S.R. Williams (1993), "The Bayesian Theory of $k$-DoubleAuctions", in D. Friedman and J. Rust (eds), The Double-Auction Market: Institutions, Theories, and Evidence, Mass.: Addison-Wesley.

[56] Schotter, A. (1990), "Bad and Good News about the Sealed-Bid Mechanism: Some Experimental Results", American Economic Association Papers and Proceedings, 80, $220-226$.

[57] Seale, D.A., T.E. Daniel, and A. Rapoport (2001), "The Information Advantage in Two-Person Bargaining with Incomplete Information", Journal of Economic Behavior and Organization, 44, 177-200.

[58] Shapiro, C., and H.R. Varian (1998), Information Rules: A Strategic Guide to the Network Economy, Boston: Harvard Business School Press. 
[59] Smith, V.L. (1982), "Microeconomic Systems as an Experimental Science", American Economic Review, 72, 923-955.

[60] Vickrey, W. (1961), "Counterspeculation, Auctions, and Competitive Sealed Tenders", Journal of Finance, 16, 8-37.

[61] Zeiliger, R. (2000), "A presentation of Regate, Internet Based Software for Experimental Economics", http://www.gate.cnrs.fr/ zeiliger/regate/regate.htm, GATE. 
